Article

\title{
Optimal Frequency Support of Variable-Speed Hydropower Plants at Telemark and Vestfold, Norway: Future Scenarios of Nordic Power System
}

\author{
Martha N. Acosta ${ }^{1,2}$, Daniel Pettersen ${ }^{2}$, Francisco Gonzalez-Longatt ${ }^{2, *} \mathbb{1}$, \\ Jaime Peredo Argos ${ }^{3}(D)$ and Manuel A. Andrade ${ }^{1}(D)$ \\ 1 School of Mechanical and Electrical Engineering, Universidad Autónoma de Nuevo León, \\ San Nicolás de los Garza 66455, NL, Mexico; martha.acostamnt@uanl.edu.mx (M.N.A.); \\ manuel.andradest@uanl.edu.mx (M.A.A.) \\ 2 Department of Electrical Engineering, Information Technology and Cybernetics, University of \\ South-Eastern Norway, 3918 Porsgrunn, Norway; 222496@student.usn.no \\ 3 Gamesa Electric, 39200 Cantabria, Spain; Jaime.peredo@siemensgamesa.com \\ * Correspondence: fglongatt@fglongatt.org
}

Received: 20 May 2020; Accepted: 19 June 2020; Published: 1 July 2020

check for updates

\begin{abstract}
The integration of renewable resources is quickly growing in the Nordic power system (NPS), and it has led to increasing challenges for the operation and control of the NPS. Nordic countries require that the first-generation power plants have a more flexible operation regime to overcomes power imbalances coming from fluctuations of the demand and supply. This paper assesses optimal frequency support of variable-speed hydropower plants installed in Telemark and Vestfold, Norway, considering future scenarios of NPS. The total kinetic energy of the NPS is expected to be significantly reduced in the future. This paper looks into the implementation of hydropower units with a variable-speed operation regime and battery energy storage systems (BESS), equipped with fast-active power controller (FAPC) technology, to provide fast frequency response after a system frequency disturbance. The frequency support was formulated as an optimization process; therefore, the parameter of the FAPC was optimally calculated for future scenarios of low inertia in NPS. Three main futures scenarios were developed for technology penetration in the Vestfold and Telemark area in Norway. The simulation results showed that the integration variable-speed hydropower units and BESS technologies improved the frequency response even in low-kinetic energy scenarios.
\end{abstract}

Keywords: battery energy store system; converter-fed synchronous machine; doubly fed induction machine; fast active power injection controller; frequency control; frequency support; future Nordic power system; kinetic energy; variable-speed hydropower plants

\section{Introduction}

Close to $80 \%$ of the electricity produced the Nordic countries is already emission-free with hydropower alone representing half of all electricity generated in the region [1]. Hydroelectricity is a significant source of energy, mainly in Nordic countries, especially in Norway. The Norwegian hydropower system was developed over a period of more than 100 years; however, the substantial capacity of the hydropower plants was installed from the 1950s until the end of the 1980s [2]. Official figures indicate the installed capacity of the Norwegian power supply system was 33,755 MW(at the beginning of 2018) and normal annual production was 141 TWh [3,4]. In Sweden, most hydropower installations are from the 1950s and 1960s [2,4]. Installed hydropower capacity in Sweden was 16,506 MW in 2018 [3]. Many of those power plants installed in Nordic countries have reached an 
age when upgrading and extension are needed, primarily because of the state of the mechanical and electrical equipment.

The modern power system is experiencing many changes. One of them is the increased volume of highly variable power generation coming from renewable resources like wind power and solar. As a consequence, the generation mix must be able to deliver a fast response in order to deal with the high variability of renewable sources. Thus, the pressure is on the traditional generation of power systems to adapt faster to variations in demand; this situation puts extra-stress on the traditional dispatchable resources such as conventional hydropower plants. The secure and economical operation of the modern power system requires the generation power plants to have a more flexible operation regime to keep the balance coming from the fluctuations coming from the demand and supply.

The majority of the hydropower plants in operation today are based in classical damp, and they are equipped with classic fixed-speed synchronous generators directly connected to the grid. They are carefully controlled in order to adapt to the system frequency (e.g., $50 \mathrm{~Hz}$ ). This approach makes the operation regime as a constant speed operation where the speed of rotation is set by the optimal speed of the hydraulic machine. The traditional hydropower plants are based on generation units equipped with traditional Francis turbines; they are designed for a wide range of heads and flows. The conventional pump and storage power plants are equipped with reversible pump-turbines to have a runner with fixed geometry. In both cases, controlling the rotational speed and efficiency of the generation units at several regimes is not always possible, the hydraulic efficiency is high at the operating design point, but it drops when the operation is changed from this point at the fixed speed.

A more attractive option is to allow the hydraulic turbine to operate at an adjustable speed, as a consequence, enabling high efficiency at load level different to operating design point. From the operational point of view, the variable speed operation of the hydro turbine is very attractive because add the needed flexibility require to tackle the balancing challenges coming from the renewable generation. The variable speed of the hydraulic turbine offers many other benefits such as [4]: extending the life-time of the turbine by reducing the tear and wear of the mechanical elements of the hydraulic turbine. Also, it produces a substantial decrease in the number of starts and stops, yielding less runner fatigue damage. Moreover, it improves efficiency with significant variation in the head, at part load and with large discharge variations. Furthermore, a lower number of generation units are needed to handle substantial variations in discharge and improves the ability to control active power in pumping mode.

The installations of the hydropower plants were forced to change due to the integration of new technologies in the power system, new market requirements, and improved designs and materials. The combination of hydropower plants with a variable speed regime and a renewable resources, like wind power and solar, seem to be a solution to maintain the balance between the generation and the demand in the Nordic power system since it is expected that $90 \%$ of the electrical production coming from wind and hydropower in the year 2050. Moreover, there are several projects of exchange energy between Nordic countries and other countries in Europe. For instance, Norway has a plan to import the excess of wind-generation from Denmark and export hydro-generation back when wind power plants have low energy production, allowing Denmark $40 \%$ of its total production to come from renewable sources. Like this example, there are projects with Netherlands, Sweden, and Finland, and there are plans for a similar project with Germany and the UK [5].

The purpose of this research paper is evaluating the future of the Nordic power system in terms of frequency stability considering the predicted decrease of the total kinetic energy and the increase of the power demand in the forthcoming 20 years. The imminent dismissing of high inertia power plants (thermal and nuclear power plants) as well as the inclusion of more intermittent sources (wind and solar power plants) raises the need to evaluate the retrofit of the existing hydropower plants. Retrofitting the conventional hydropower plants by including variable speed regime using converter-fed synchronous machines and doubly fed induction machine is the most viable option for the Nordic power system, due to the high dependence on energy production coming from hydropower 
plants that it will experience in the upcoming years and in addition to the capability to regulate the frequency and efficiency that these variable speed technologies offer. Furthermore, the installation of the battery energy storage system in the Nordic power system is considered, since it can provide fast frequency support, it can contribute to system inertia, and its costs have been decreasing in recent years. These three technologies are equipped with a frequency sensitive control that determines the amount of active power that will be delivered to face a frequency disturbance. It is of interest to evaluate how those technologies can improve the frequency response facing the decreasing kinetic energy when a disturbance occurs. To carried out this study a portion of the Norwegian power system was modelled in DIgSILENT ${ }^{\circledR}$ PowerFactory ${ }^{\mathrm{TM}}$, and a set of future scenarios were defined following the predicted changes on the Nordic power system in the next 20 years. The parameters of the frequency sensitivity control were optimized to provide optimal frequency support to the Nordic power system and enhance the frequency response. The improvement of the frequency response was evaluated by computing several frequency indicators.

The rest of this paper is organized as follows: Section 2 presents a detailed description of the pumped-storage hydropower plants and the variable-speed hydro plants. Section 3 introduces the principle of the battery energy storage system. Section 4 describes the frequency control optimization, its formulation and the frequency indicators. Section 5 is dedicated to present the future scenarios of the Nordic power system for the period 2020-2040. Section 6 presents the result of evaluating the defined future scenarios. Section 7 provides the main conclusions of this research paper.

\section{Pumped-Storage Hydro Plants (PSHPs)}

Hydropower has been a source of mechanical power since ancient times, used to grind flour but also for many other tasks. One of those tasks is producing electricity, and for this purpose, hydropower is used for four different approaches: conventional (dams), pumped-storage (PS), run-of-the-river (ROR), and tide. The conventional dams are the most widely used approach to hydropower production. Norway has more than 900 hydropower plants, and they provide nearly $96 \%$ of its electricity, making it the sixth-largest hydropower producer in the world. On the other hand, an opportunistic approach of using hydropower production is the so-called pumped hydro storage (PHS); it is the oldest technology for large-scale energy storage. Around $1392 \mathrm{MW}$ of the total installed capacity $(33,755 \mathrm{MW})$ in Norway are PHS, and there is more potential by retrofitting or updating the installed hydropower plants. The PHS uses a convenient and straightforward principle with two water reservoirs located at different altitudes; when water is released from the higher reservoir to the lower reservoir the kinetic energy of the water flow released is used by the hydro turbine and generator to produce electricity. There is the possibility of using electricity from the power grid to refill the higher reservoir by using the hydro turbine in pump operation mode.

\subsection{Variable-Speed Operation of PSHP}

Several types of runners are available for hydropower plant application: Pelton, Francis, and Kaplan. Traditionally, the hydropower units are optimally designed to operate a specific rotational speed, head, and discharge. Thus, a fixed speed operation regime allows only very limited deviations of head and discharge because of its geometry. The hydraulic turbine may reach its maximum efficiency of energy conversion, cavitation and vibration-free operation when working at rated conditions (rotational speed, head, and discharge). The hydraulic efficiency curve for fixed speed operation is designed so that the efficiency is highest at the best point for which the turbine is designed. Therefore, if the operating point is moved away from the best point, the efficiency drops. The Francis turbine type is one of the most flexible runners because it allows a wide variation of the operation discharge. However, changes in the head results in an extreme reduction on hydraulic efficiency and the variable speed operation can be particularly advantageous in Francis turbines with high specific speed $\left(n_{q A}\right)$. 
The steady-state operation of a hydraulic runner, such as the Francis turbine, is characterized by the rotational speed $(n)$ and the discharge $(Q)$ :

$$
\begin{gathered}
n_{11}=\frac{n D}{\sqrt{H}} \\
Q_{11}=\frac{Q}{D^{2} \sqrt{H}}
\end{gathered}
$$

where $H$ is the nominal head (m), $Q$ the rated discharge $\left(\mathrm{m}^{3} / \mathrm{sec}\right), n$ the nominal speed (rpm), and $D$ the runner diameter $(\mathrm{m})$. The above equation can be used to create the topographic curves for a given turbine of pump-turbine working in turbine mode, also known as a Hill diagram (see Figure 1). For a typical Francis turbine, the efficiency hill chart is given in unit values $n_{11}-Q_{11}$ where unit speed $\left(n_{11}\right)$ and unit discharge $\left(Q_{11}\right)$ are given in (1)-(2) and the unit power $\left(P_{11}\right)$ is calculated as:

$$
P_{11}=\frac{P}{D_{1}^{2} \sqrt{H^{3}}}
$$

where $P$ is the power input of the turbine (typically in MW).

The values $n_{11}$ and $Q_{11}$ lies close to the best point of operation ('bep' in Figure 1) that gives the best efficiency of the runner. Consider a hydraulic turbine working at the 'bep' (1) and then the operating is shifted to (2) (discharge and speed maintained but the head is reduced) as a consequence the efficiency drops from $\eta_{1}$ to $\eta_{2}$. Recovery to $\eta_{3}$ efficiency (3) is possible by reducing the speed to $n_{4}$, with further improvement possible (4),(5) by decreasing the discharge (from $Q_{4}$ to $Q_{5}$ ).

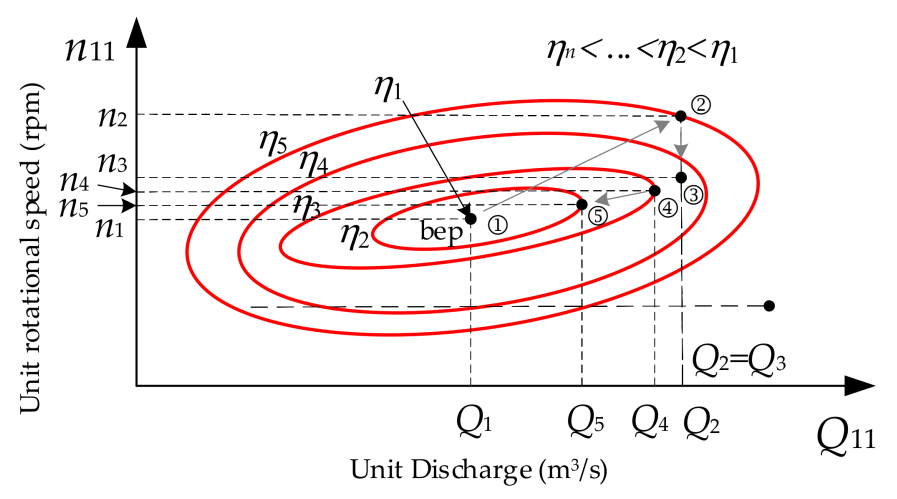

Figure 1. Hill diagram showing the topographic curves of efficiency for a pump-turbine operating in the turbine mode.

From the previous analysis, it is shown that the turbine efficiency is higher for variable speed operation than for fixed speed operation, but that the efficiency gain is smallest at the best point of operation at rated power and head. Some scientific publications have demonstrated that the hydraulic efficiency would be 3-10 percentage points higher for variable speed than for conventional operation $[4,6]$.

Figure 2 shows representative hydraulic turbine efficiency curves over a range of head and power output for both single and adjustable speed units. From this figure, it is clear the hydraulic efficiency gain is most significant at low power outputs and low head $[7,8]$. There is some additional efficiency gain at operation above rated power and rated head, but the main benefits of variable speed operation are achieved at operation below the best point [4].

There are several advantages of the variable speed of the hydraulic turbines. However, traditional hydropower units are not designed to operate at variable speeds; in fact, they are designed and built to operate at a fixed speed to obtain a constant frequency by using a classical synchronous generator 
directly connected to the power networks. The authors in Reference [6] found that by using a DC rather than an AC link, it was no longer necessary to tie the generator synchronously to the system frequency; in fact, the speed of the hydraulic turbine could be adjusted freely to satisfy the load demand at the maximum possible hydraulic efficiency. The results in Reference [6] indicated that in addition to an increased hydraulic turbine efficiency of a partial load, the efficiency of large synchronous machines operated with loads lower than the rated output power had been found to increase with variable speed operation $[4,6]$. At partial loading, down to $40 \%$ of rated power, the efficiency of the synchronous machine was found to increase by up to one percentage point [4].

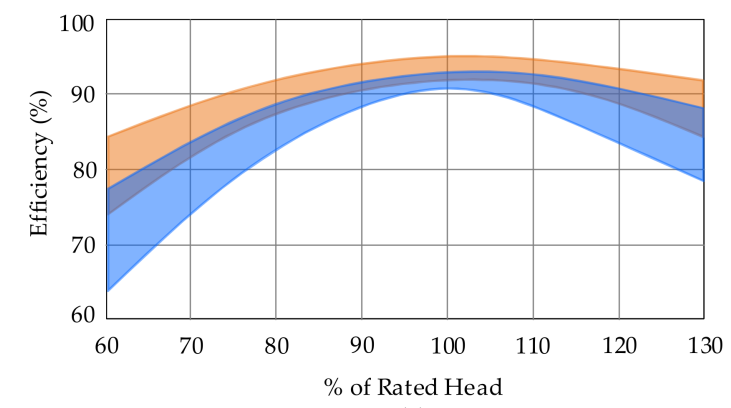

(a)

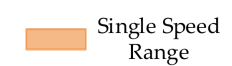

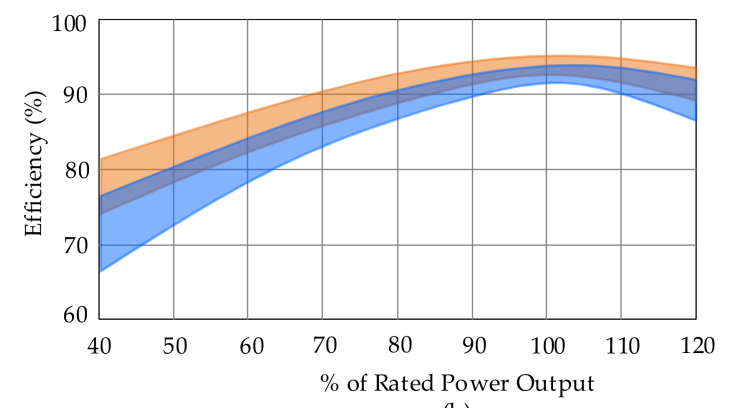

(b)

Figure 2. Hydraulic turbine efficiency (\%) versus: (a) rated head (\% of the rated value) and (b) rated power output ( $\%$ of the rated output power), considering fixed-speed and variable-speed operation.

The first implementations of variable-speed technology started during the early 1990s, and it was mainly dedicated for reversible pump-turbines (RPTs) installed at pumped-storage power plants in Japan and Europe. Installations of this technology were recently done for pumped-storage projects in India and China [9], Slovenia [10], Japan [11], South Africa [12], and Switzerland [13].

\subsection{Generator Technologies for Variable-Speed Operation of PSHP}

The variable operation of the hydro turbine offers many advantages, and the majority of the generation technologies used to enable variable speed use of power electronics converters. Two technologies are the most used today to achieve the variable-speed operation conditions in hydropower units [14]:

- Doubly fed induction machines (DFIMs);

- Converter-fed synchronous machines (CFSMs).

The CFSM is recognized to have superior performance, but one crucial drawback to this technology is that it requires a fully rated power electronic converter (FRPEC), the use of a FRPEC implies a high-cost, and it is not suitable for high power levels. As a consequence, the DFIM results to be a more attractive option for variable-speed hydro turbines at high power levels applications, because the power electronic converter itself can be considerably smaller (size of converter $\sim 10 \mathrm{~m}^{3} / \mathrm{MVA}$ [12]), as it is not rated to $100 \%$ of the generator capacity as in the CFSM.

\subsubsection{Doubly Fed Induction Machines (DFIMs)}

Doubly fed induction machines (DFIMs) have been used for many years in variable speed wind turbines, with a successful market share in modern wind farms. The DPIM for variable speed application has been proved, and it is a very mature option for the development of variable-speed hydropower units; in fact, this technology has been applied for pumped storage plants [14] with power ratings up to 400 MVA.

Figure 3 shows a general scheme of a DFIM used for a variable-speed hydro turbine. The DFIM is coupled to the hydro turbine, the DFIM stator is directly connected to the grid, while the rotor windings 
are connected via a power electronic converter, using slip rings. The power electronic converter consists of a back-to-back converter, i.e., rotor side converter (RSC) and grid-side converter (GSC), which has a power rating on the partial scale of the DFIM rated power. The DFIM uses the exchange between the wound rotor and the power electronic converter to provide the speed variation. Therefore, the stator needs to be oversized in sub-synchronous mode, due to the additional power transiting from the rotor to the stator. The power electronic converter is rated to a lower than the generator capacity, as power just needed to feed the excitation, which is a function of the expected speed variation. The DFIM rotors typically have two to three times the number of turns of the stator, leading to a higher rotor voltage and lower current [15]. Doubly fed induction machine technology is generally the preferred solution for large unit outputs (>100 MW) [16].

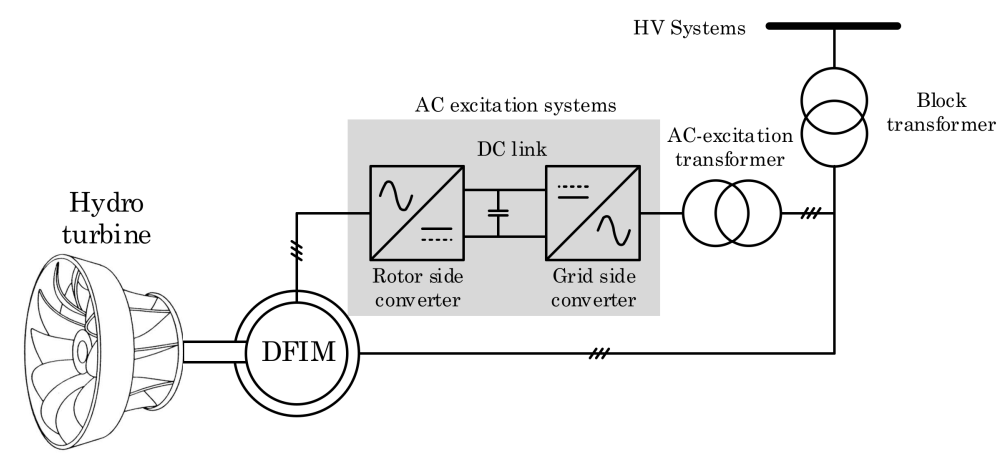

Figure 3. Schematic representation of asynchronous variable speed with doubly fed induction machines (DFIM) technology.

\subsubsection{Converter-Fed Synchronous Machines (CFSMs)}

Converter-fed synchronous machine (CFSM) technologies use a classical synchronous machine that is connected to the power system via a full-rated power electronic converter.

Figure 4 shows a general scheme of a CFSM used for a variable-speed hydro turbine. Typically, a back-to-back voltage source converter (VSC) is used to connect two AC sides using a DC link. The back-to-back power electronic converter allows decoupling the frequency of the synchronous machine from the AC grid, allowing a wide range of rotor speed and frequency variation. The generated variable frequency is converted into DC power before being inverted to AC power in a desired continuously frequency that is the synchronous frequency of the power system. As all generated power must pass through the power electronic converters, they must be rated to the full power of the generator with a relatively high cost, as a consequence, the application of the CFSM is limited to relatively low power ratings ( $<100 \mathrm{MW}$ ) [17]. Also, another important consideration of the CFSM is the space required to accommodate a new generation unit. Finally, another element to consider in the CFSM is the efficiency drops due to the losses in the back-to-back converter [17].

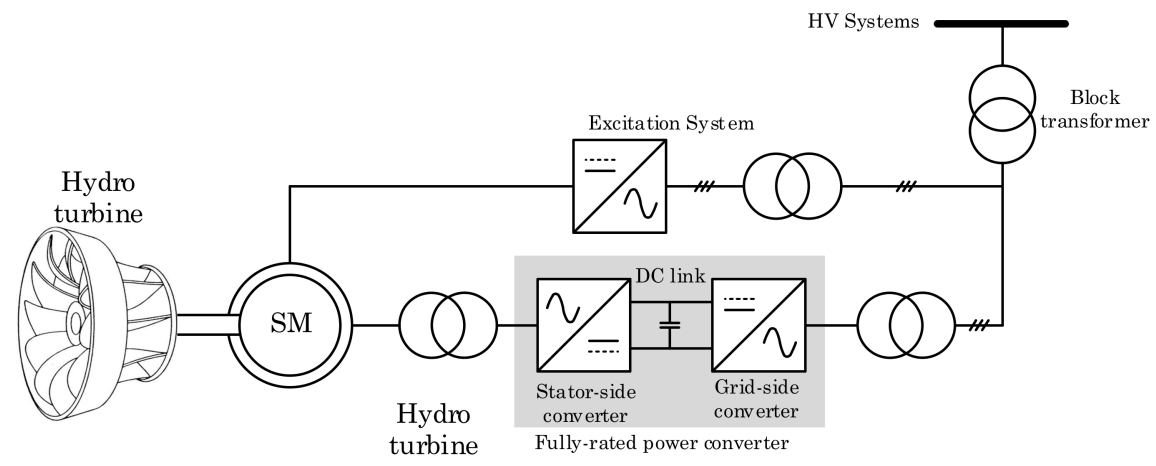

Figure 4. Schematic representation of synchronous variable speed with converter-fed synchronous machine (CFSM) technology. 


\section{Energy Storage System to Support Hydropower Sources in the NPS}

Hydropower units have two main characteristics that have made them take a prominent role in the power system: are categorized as a renewable resource and have higher controllability compared to both wind and solar power. Moreover, hydropower turbines as today provide a natural inertial response. This characteristic is crucial for frequency control purposes, especially as the low inertia scenarios in the NPS, as caused by the decommissioning of high inertia power sources (nuclear, thermal) and the grown replacement by intermittent sources (wind, solar) with low inertia [18]. This paradigm change makes it necessary to introduce new technologies that can be used to give support and help to maintain system frequency. The use of energy storage systems (ESSs) has gotten a much more significant role to keep the balance in the power system by storing energy and converting it back when it is needed [19]. The global database for the Department of Energy (DOE based in USA), which was last updated 18th February 2020, shows that there are over 1600 ESSs projects in the world: 763 of battery energy storage system (BESS), 350 of pumped hydro storage, 53 of the flywheel, 29 of the supercapacitor, and the rest belong to another kind of ESSs [20]. Most of the projects are combined with wind or solar plants, but they could also be combined with hydropower generation units to increase the flexibility of the units. Of the technologies that are currently on the market, BESS seems to be the best suited to increase the stability of the system in cooperation with hydropower units because it offers very high efficiency and energy density, fast response and has long time life [21]. Therefore, in this research paper, BESS technology is integrated into combining with the variable speed technologies as an alternative to facing the dropping of system inertia in the future years.

\section{Battery Energy Storage System}

The battery energy storage system (BESS) follows a process of three main stages consisting of converting the electrical energy into another energy form, the storage of the transformed energy during a period of time, and the transformation of the stored energy into electrical energy again. Those three steps are related to three main subsystems [22]:

1. Power conversion system: this subsystem consists of an electrical or an electromechanical device that allows converting electrical energy;

2. Battery energy system: the principal element of this subsystem is an electromechanical energy storage technology (battery) to store/deliver the energy;

3. The controllers associated to the BESS: this subsystem has a set of controllers that can be divided into two categories: (i) fast inner controller is directly connected to the power conversion system and is related to the control of the converter's AC currents of the $d q$-axis, and (ii) slow outer controllers groups three controls $P-Q$ control, fast active power control, and battery charge control.

\section{Frequency Control Optimization}

This section is dedicated to describing the frequency control considering the TSO/DSO iterations. Moreover, it is fully explained the fast-active power controller as a control strategy to provide fast frequency response to the power system. Finally, the frequency control optimization is the formulate based on the gain of the FAPC installed at the DFIM, CFSM, and BESS technologies to minimize the maximum frequency deviation following a system frequency disturbance.

\subsection{Frequency Control and TSO/DSO Interactions}

The increasing integration of intermittent power sources such as wind and solar plants has created an intrinsic uncertainty in the power balance between the production and the consumption of energy in the power system. This issue has limited the transmission systems operators (TSOs) operational capabilities, and the power system security has become dependent on the intermittent power sources available in the distribution network. To counteract the effects of low inertia, TSOs have resorted to the use of ESSs installed in the distribution network to provide fast frequency response (FFR) by absorbing 
or injecting active power to the grid. Therefore, the interaction of the TSOs and the distribution system operators (DSOs) can help to balance the power supply and as a consequence has an effective frequency control [23].

The TSO/DSO interactions can be described considering a transmission system equipped with $N_{S G}$ synchronous generators connected to $N_{D S}$ distribution systems through sub-transmission networks which contains power transformers and protection equipment. After a power imbalance, in the primary frequency control period, the dynamic of the automatic voltage regulation and power system stabilizer can be overlooked, and the frequency dynamics can be written using the swing equation [24]:

$$
\begin{gathered}
\frac{2 H_{k}}{\omega_{0}} \frac{d w_{k}}{d t}=P_{m, k}-P_{S G, k}-D_{k}\left(\omega_{k}-\omega_{0}\right) \\
\frac{d \delta_{k}}{d t}=\omega_{k}-\omega_{0} \quad \forall k=1,2, \ldots, N_{S G}
\end{gathered}
$$

where $\omega_{k}$ is the angular speed, $D_{k}$ is the damping coefficient, $H_{k}$ is the inertia constant, $P_{m, k}$ is the mechanical power, and $P_{S G, k}$ is the electrical power of the $k$-th synchronous generator. Moreover, $\omega_{0}$ is the nominal angular speed.

Meanwhile, the FFR support to the TSO from the DSOs consider the contribution of the active power delivered by the ESSs installed in the grid. This paper considers three technologies that can provide FFR support to the power system: DFIM, CFSM, and BESS. The DSO is denoted by the network model of Vestfold and Telemark area in Norway connected to the TSO represented by the Nordic power system (NPS) equivalent. The total active power contributing to FFR $\left(P_{F F R C}\right)$ can be written as:

$$
P_{F F R C}=\sum_{i=1}^{N_{D F I M}} P_{D F I M, i}+\sum_{j=1}^{N_{C F S M}} P_{C F S M, j}+\sum_{k=1}^{N_{B E S S}} P_{B E S S, k} \quad \forall\left\{\begin{array}{c}
i=1,2, \ldots N_{D F I M} \\
j=1,2, \ldots N_{C F S M} \\
k=1,2, \ldots N_{B E S S}
\end{array}\right.
$$

where $P_{D F I M, i}$ represent the active power of the $i$-th DFIM, $P_{C F S M, j}$ is the active power of the $j$-th CFSM and $P_{B E S S, k}$ is the active power of the $k$-th BESS.

\subsection{Fast Active Power Controller (FAPC)}

The natural resistance of the synchronous generator to angular acceleration after a disturbance comes from an inherent physical characteristic of its rotor, called inertia. This rotational inertia offers to damp to the frequency. The scientific literature presents several controllers trying to mimic the behavior of the synchronous generator by using power electronic converters (PECs). The main objective of the PECs-based controllers enabling FFR of the PEC by injecting/absorbing active power using the local measured frequency [25].

The fast-active power (FAP) controller is an FFR model that uses the frequency deviation to regulate the injection/absorption of the active power of the PEC. The FAP controller injects active power when the power system has an under-frequency condition, and it absorbs active power when the power system is facing an over frequency condition. Moreover, the energy available in the DC side of the PEC determinates its limits of operation. The FAP controller is able to deliver the fully active power in less than one second typically after measurement of frequency deviation [26]. According to the classical control theory, the FAP controller can be modelled implementing two strategies: proportional control action and derivative control action. The proportional control action approach is used in this paper.

The proportional control action is linear feedback control in which the controlled variable is adjusted by a gain that is proportional to the deviation of the measured value from the desired value. In the proportional FAP (PFAP) controller the controlled variable is the active power, the desired value is the nominal frequency $\left(f_{0}\right)$, and the frequency deviation $(\Delta f)$ is represented by the difference between $f_{0}$ and the local measured frequency $(f)$. Moreover, the gain is the droop coefficient $\left(K_{d}\right)$ of the ESS. Considering a dead band, saturation and that $K_{d}$ can be varying between a range of values, i.e., $K_{d} \in\left[K_{d, \min }, K_{d, \max }\right]$, the power-frequency characteristic of the PFAP controller is shown in Figure 5. 


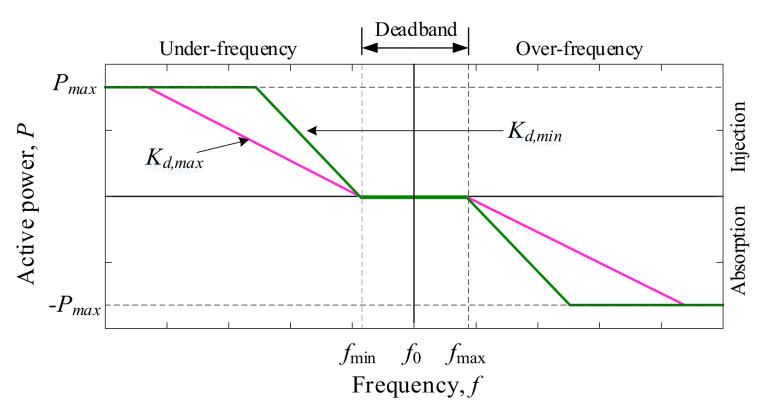

Figure 5. Power-frequency characteristic of the proportional fast active power (PFAP) controller.

Mathematically speaking, the PFAP controller is described as follows:

$$
P=\left\{\begin{array}{cl}
K_{p} f & \text { absortion if } f>f_{\max } \\
0 & \text { not acting if } f_{\min } \leq f \leq f_{\max } \\
-K_{p} f & \text { injection if } f<f_{\min }
\end{array}\right.
$$

\subsection{Optimization of the System Frequency Response}

The classical synchronous generator response to a power imbalance is defined by the amount of the kinetic energy stored on the rotating masses and the droop value used in the governors of the synchronous generators. These two variables influence the frequency response of the power system and therefore, the amount of active power provided by the generators to recover the balance between generation power and demand power. The imminent substitution of power plants based on synchronous generators by new technologies such as DFIM, CFSM rise the need to analyze the repercussions that they have on the frequency response. Since the DFIM, CFSM technologies are equipped with fast active power injection controllers, the frequency response of the power system can be substantially improved by the appropriate amount of active power contribution. Therefore, it is of utmost importance defining the correct settings of the droop coefficient $\left(K_{d}\right)$ of the PFAP controller.

This section is dedicated to presenting the main frequency response characteristics and describing the optimization approach used to compute the optimal settings of the droop coefficients.

\subsubsection{Frequency Response Indicators}

The power system requires several control actions to maintain the balance between the power generation and the power demand, one of them is the primary response or primary frequency control. The primary response typically takes place within the first 10-30 s after a frequency event occurs, and it is very important since it acts to reduce de frequency deviation. The synchronous generators cannot restore a power imbalance instantaneously. Therefore, the KE stored in rotating masses acts in a small-time frame (typically less than $10 \mathrm{~s}$ ) to arrest the frequency deviation, until the governor is activated. As a consequence, the primary response involves two processes: the inertial response and governor action, as shown in Figure 6. Due to the PFAP controllers are a sensitivity frequency control, the active power is delivered with a very short time-delay, and its rate of change can be proportional to the rate of change of frequency (see Figure $6 b$ ).

The main frequency response indicators are illustrated in Figure $6 \mathrm{a}$ and are defined following [27]:

- Minimum frequency $\left(f_{\min }\right)$ : denotes the minimum value that the frequency reaches during the transient response after a frequency event. It is computed as the difference between the nominal frequency $\left(f_{0}\right)$ and the maximum frequency deviation $\left(\Delta f_{\max }\right)$ during the transient response, i.e., $f_{\min }=f_{0}-\Delta f_{\max }$.

- Minimum time $\left(t_{\min }\right)$ : is the time at which the frequency reaches its minimum value $\left(f_{\min }\right)$ and its maximum deviation $\left(\Delta f_{\max }\right)$. The inertial response begins from the disturbance start $\left(t_{s}\right)$ until the frequency reaches its minimum value at $t_{m i n}$; after that, the governor action initiates. 
- Rate of Change of Frequency (ROCOF): represents the speed at which the frequency changes in one second, i.e., it is the time derivative of the frequency and it is described as $R O C O F=d f / d t(\mathrm{~Hz} / \mathrm{s})$.

- Steady-state frequency $\left(f_{s s}\right)$ : is the value at which the frequency settle, typically is after the inertia response and the governor action, at this point, the ROCOF is zero. This indicator gives a measure of the ability of the power system to recuperate after a frequency event.

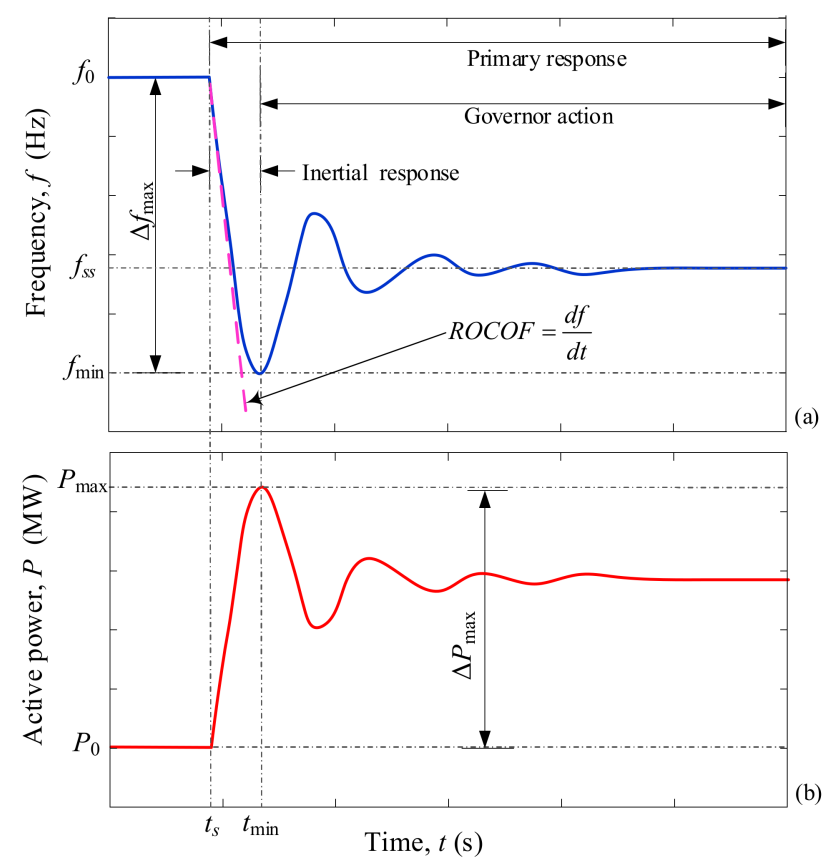

Figure 6. (a) frequency response and (b) active power contribution by the proportional fast active power (PFAP) controller of a power system after a frequency event.

\subsubsection{Optimization Problem}

The volume of active power delivered by PFAP controllers, to arrest the frequency decaying, depends on the $K_{d}$ value. Therefore, the main objective is formulating the problem of determining the settings of $K_{d}$ as an optimization problem which allows minimizing the maximum frequency deviation $\left(\Delta f_{\max }\right)$ by supplying the proper amount of active power.

\section{Decision Variables}

The optimization problem is formulated considering the technologies for variable speed operation (i.e., DFIM and CFSM) and the battery energy storage system (BESS). The droop coefficients of these three technologies were used as decision variables. The set of decision variables of each technology were vectorially expressed as:

$$
\begin{aligned}
& \mathbf{K}_{\alpha}=\left[\begin{array}{llllll}
K_{d, \alpha, 1} & K_{d, \alpha, 2} & \cdots & K_{d, \alpha, i} & \cdots & K_{d, \alpha, N_{\alpha}}
\end{array}\right] \forall i=1,2, \ldots N_{\alpha} \\
& \mathbf{K}_{\beta}=\left[\begin{array}{llllll}
K_{d, \beta, 1} & K_{d, \beta, 2} & \cdots & K_{d, \beta, j} & \cdots & K_{d, \beta, N_{\beta}}
\end{array}\right] \forall j=1,2, \ldots N_{\beta} \\
& \mathbf{K}_{\gamma}=\left[\begin{array}{llllll}
K_{d, \gamma, 1} & K_{d, \gamma, 2} & \cdots & K_{d, \gamma, k} & \cdots & K_{d, \gamma, N_{\gamma}}
\end{array}\right] \forall k=1,2, \ldots N_{\gamma}
\end{aligned}
$$

where $K_{d, \alpha, i}$ is the droop coefficient of the $i$-th DFIM, $K_{d, \beta, j}$ is the droop coefficient of the $j$-th CFSM and $K_{d, \gamma, k}$, is the droop coefficient of the $k$-th BESS. $N_{\alpha}, N_{\beta}$, and $N_{\gamma}$ is the number of DFIM, CFSM and BESS connected to the power system, respectively. Computing the optimal settings of $K_{d}$ the active power injection by the PFAP controller is defined, and the frequency response can be improved. 
Therefore, the decision variable vector $(\mathbf{x})$ is comprised of $K_{d}$ of all technologies equipped with the PFAP controller (i.e., DFIM, CFSM, and BESS), and it is written as:

$$
\mathbf{x}=\left[\begin{array}{lll}
\mathbf{K}_{\alpha} & \mathbf{K}_{\beta} & \mathbf{K}_{\gamma}
\end{array}\right]_{1 \times\left(N_{\alpha}+N_{\beta}+N_{\gamma}\right)}
$$

The decision variables were constricted by considering the upper and lower limits to maintain the setting values of the PFAP controllers inside realistic physical values. The upper and lower limits are defined as:

$$
\begin{aligned}
& \mathbf{K}_{\alpha}^{\mathrm{L}}<\mathbf{K}_{\alpha}<\mathbf{K}_{\alpha}^{\mathrm{U}} \\
& \mathbf{K}_{\beta}^{\mathrm{L}}<\mathbf{K}_{\beta}<\mathbf{K}_{\beta}^{\mathrm{U}} \\
& \mathbf{K}_{\gamma}^{\mathrm{L}}<\mathbf{K}_{\gamma}<\mathbf{K}_{\gamma}^{\mathrm{U}}
\end{aligned}
$$

where the superscripts $\mathrm{L}$ and $\mathrm{U}$ indicate the lower and upper bounds of the droop coefficients of $\operatorname{DFIM}\left(\mathbf{K}_{\alpha}\right)$, droop coefficients of CFSM $\left(\mathbf{K}_{\beta}\right)$, and droop coefficients of BESS $\left(\mathbf{K}_{\gamma}\right)$, respectively.

\section{Objective Function}

The constant change in the production of energy or its demand cause second-by-second small variations in the system's frequency. When a power imbalance occurs (generally caused by the sudden increase of demand or an outage of single/multiple generation units) the system frequency decrease. The depth to which the system frequency drops $\left(f_{\min }\right)$ depends on the amount of the kinetic energy stored on the synchronous generators. If the frequency falls too low, the under-frequency relays may be activated the load shedding to arrest the frequency decaying and recover the frequency. To avoid the activation of the under-frequency protections and, therefore, the unnecessary disconnection of loads, it is essential to limit the drops of the frequency by minimizing the maximum frequency deviation $\left(\Delta f_{\max }\right)$.

As it was intended to minimize the maximum frequency deviation regardless of where in the system the disturbance occurs, the frequency of the power system was represented adopting the concept of center of inertia (COI). The frequency of the center of inertia $\left(f_{\mathrm{COI}}\right)$ was computed as the inertia weighted average of the frequencies of all generators connected to the power system. Mathematically speaking, $f_{\mathrm{COI}}$ is written as [22]:

$$
f_{\mathrm{COI}}=\frac{\sum_{i=1}^{N_{G}} H_{i} f_{i}}{H_{\mathrm{T}}}
$$

where $H_{i}$ and $f_{i}$ are the inertia constant and frequency of the $i$-th generator, respectively. $H_{\mathrm{T}}$ is the total system inertia computed as $\sum_{i=1}^{N_{G}} H_{i}$ and $N_{G}$ is the number of generators connected to the power system.

The objective function to minimize the maximum frequency deviation of the center of inertia $\left(\Delta f_{C O I, \max }\right)$ is written as:

$$
\min _{\mathbf{x}}[f(\mathbf{x})]=\min _{\mathbf{x}}\left[\Delta f_{\mathrm{COI}, \max }(\mathbf{x})\right]=\left|f_{0}-f_{\mathrm{COImin}}\right|
$$

\section{Defining of Future Scenarios}

This section is dedicated to defining a series of possible scenarios for the integration of DFIM, CFSM, and BESS technologies. The future scenarios were constructed taking into account the technological advances that would have been done in the most recent years, the market/policies of today, and the future Nordic power system.

\subsection{Nordic Power System (NPS)}

The Nordic power system (NPS) is the synchronous power system that spans the four countries of Denmark, Finland, Norway and Sweden. No significant changes in the installed capacity of hydropower in the NPS were expected, but there was a shift from the use of conventional power sources, such as 
thermal power and nuclear power, to more intermittent sources [2]. Table 1 shows an overview of the expected variations in the production of wind, thermal, and nuclear power in the interval from 2020 to 2040 .

Table 1. Power generation in the NPS in the period 2020-2040 [2].

\begin{tabular}{ccccc}
\hline Source & $\mathbf{2 0 2 0}(\mathrm{GW})$ & $\mathbf{2 0 3 0}(\mathrm{GW})$ & $\mathbf{2 0 4 0}(\mathrm{GW})$ & Change 2020-2040 (\%) \\
\hline Wind & 20 & 30 & 45 & +125 \\
Thermal & 8 & 5 & 3.5 & -56 \\
Nuclear & 12 & 10.5 & 2.5 & -79 \\
\hline
\end{tabular}

Table 1 shows that the majority of the nuclear power in the NPS will be decommissioned before 2040 and that the reduction in nuclear power will be compensated by an increase in wind power. The wind turbines will not be placed in the same location as the nuclear power plants, and this will change the layout and composition NPS in the future. The NPS will have a more significant percentage of intermittent power sources that is located further from the loads, which will put a more significant strain on the transmission grid.

The load is estimated to increase in the coming years, and they estimate that it will reach a peak load of $79 \mathrm{GW}$ in 2040, the relationship between the estimated production and consumption in the NPS in the coming years is shown in Figure 7.

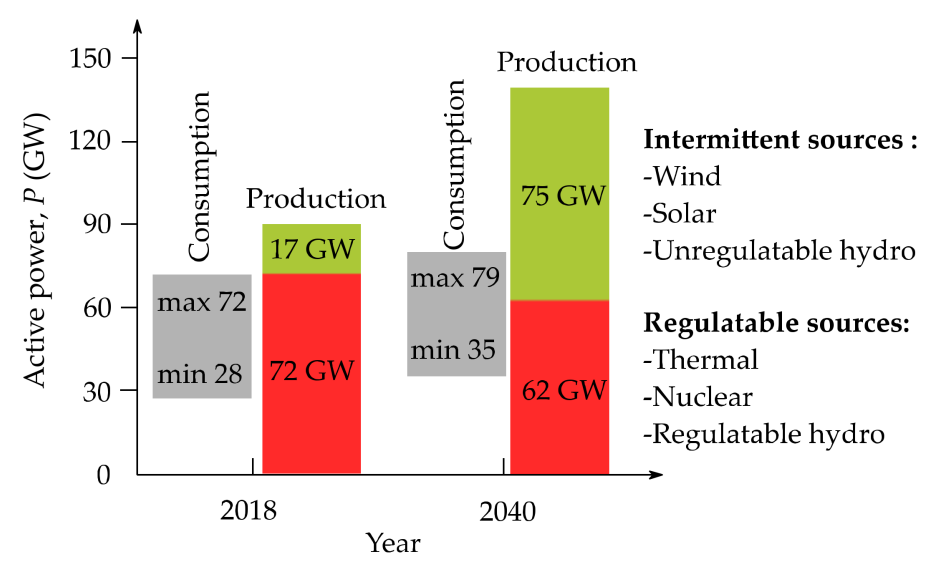

Figure 7. Production and consumption in the NPS (2018) and forecast by 2040 [3].

Figure 7 shows that it is estimated that the peak consumption in the NPS will exceed the installed capacity of regulated power production. This means that the NPS will be reliant on the intermittent power production and imports, to ensure the system stability, and prevent the need for load shedding. This will also make it very important that the regulated power production is flexible so that it can be used to keep the system stability.

A report carried out in 2016 by the Nordic TSOs highlights five key subjects as the main future challenges for the Nordic grid [4]:

- System flexibility;

- Generation adequacy;

- Frequency quality;

- System inertia;

- Transmission adequacy.

The main causes of these issues are the transition to a more electrified society (system flexibility, generation, and transmission adequacy), the decommission of nuclear power and greater penetration of wind and solar (system inertia, generation and transmission adequacy) and the overall decrease in 
the system inertia (frequency quality and system inertia). These issues led the Swedish TSO to carry out a survey, which looked on the future market situation until 2040 for the NPS, which included their estimation of the future development of the system inertia, which is shown in Figure 8.

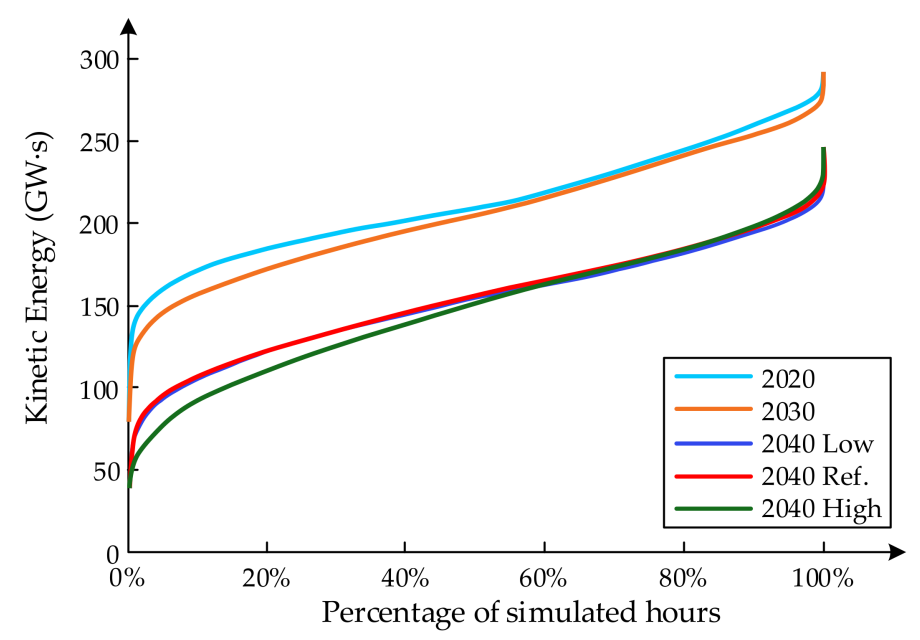

Figure 8. System inertia in the NPS for the period 2020-2040 [5].

Figure 8 shows that the inertia in the NPS will decrease gradually over the next couple of decades. One important factor for the year 2020 is the low inertia situations is presented in periods with a low load in the NPS, in contrast, for the year 2040, a portion of the low inertia condition is produced at hours with a high system load.

This also shows that it is necessary to introduce new sources of system inertia, to replace the high inertia sources that are planned to be decommissioned in the next 20 years. This is required to ensure that the system inertia does not reach a critically low level, which will lower the frequency quality and make the system vulnerable for fault situations. Another major factor that has to be considered is that Sweden is planning to decommission all of its Nuclear power production in the next 20-30 years. This means that the rotational inertia of the NPS is considered to decrease in the same time period, as the nuclear powerplants are getting decommissioned. The estimated rotational inertia that will be used in the simulation is shown in Table 2, and the values are taken from Figure 8.

Table 2. Rotational energy in the NPS (GW·s) for the period 2020-2040.

\begin{tabular}{cccc}
\hline Level & $\mathbf{2 0 2 0}$ & $\mathbf{2 0 3 0}$ & $\mathbf{2 0 4 0}$ \\
\hline High & 260 & 255 & 190 \\
Low & 174 & 159 & 105 \\
\hline
\end{tabular}

The peak load of the NPS is expected to increase in the simulation period to around 79 GW in 2040. The estimated load for the simulation period 2020-2040 is shown in Table 3, and it is estimated from Figure 7.

Table 3. System load of the NPS (GW) for the period 2020-2040.

\begin{tabular}{cccc}
\hline Level & $\mathbf{2 0 2 0}$ & $\mathbf{2 0 3 0}$ & $\mathbf{2 0 4 0}$ \\
\hline High & 72.6 & 75.8 & 79 \\
Low & 28.6 & 31.8 & 35 \\
\hline
\end{tabular}

\subsection{Future Scenarios}

The major waterways in the NPS are already used for hydropower production or are considered as natural reserves, so it is not expected that there will be built out any new big hydropower plants in the 
100MW class in the near future. Therefore, the most significant evolution in the hydropower production in the NPS will be the reinvestment or expansion of already existing powerplants. This reinvestment or expansion can vary from a reduction the friction of the shafts to increase the overall efficiency of the plant, to overhauling the complete powerplant, which includes building a new power station with the state-of-the-art control units and turbines. The decrease of rotational energy and the increase of the general load is decreasing the overall system stability, and this means that the system gets more vulnerable for disturbances. The scenarios in this paper will look into the impact of introducing hydropower generation units with a variable speed operation regime and battery energy storage systems on system stability.

The scenarios are built considering ten-year interval at 2020, 2030 and 2040. Each ten-year interval considers three main scenarios:

- Scenario 0: This scenario considers only the maintenance action of the existing hydropower units in the system. Therefore, new types of technologies are not integrated into the system; the purpose of this scenario is observing the performance of the NPS to a disturbance with the existing conventional power plants based on synchronous generators any other technology is assumed to be no frequency sensible.

- Scenario 1: In this scenario, some significant hydropower generation (greater than $100 \mathrm{MW}$ ) will be replaced with DFIM units and medium hydropower generation units (less than $100 \mathrm{MW}$ ) will be substituted with CFSM units. This will be done in two intervals: three units will be replaced in the year 2030, and an additional four will be replaced in the year 2040. This scenario will mainly focus on looking into how the implementation of variable-speed hydro will impact the overall system frequency stability.

- Scenario 2: This scenario follows the same pattern as Scenario 1, but also it will include the installation of five BESSs, one will be introduced in the year 2030, and the remaining four will be implemented in the year 2040. This scenario investigates the benefits related to the system stability installing BESS in the NPS.

The scenarios defined above will be focused on the case of the low rotational energy since it represents the critical operation of the NPS.

\subsubsection{Year 2020}

For the year 2020, the model is used as it is, without any changes to the NPS model. This year will be used as a reference point, to see how the future scenarios will compare to the current state of the NPS. Therefore, only Scenario 0 will be performed considering the amount of low rotational energy established for this year in Table 2.

\subsubsection{Year 2030}

The year 2030 will experience a slight drop in rotational energy, as the most significant drop of rotational energy is expected to happen in the interval 2030-2040, as the Swedish nuclear powerplants will be decommissioned because of old age. Therefore, it is not expected to be any major changes in the stability of the NPS in this year. The DFIM technologies are expected to be the dominant solution with variable-speed hydro for high power applications, so any big powerplants over $100 \mathrm{MW}$ will be built with the use of DFIM, while smaller powerplants under $100 \mathrm{MW}$ will use CFSM technologies as the preferred solution. The battery energy storage system could still be considered as too expensive to be implemented in the NPS, because of the low power prices, but it could be possible that there will be implemented a demo installation of batteries at one of the smaller hydropower plants, to see how it can be implemented in the NPS in the future. 
Scenario 0

For this scenario is it only expected to be done maintenance and retrofitting to a level that all the power stations have the same capabilities as they have in today's NPS. The total kinetic energy of the NPS decreases $8.62 \%$ concerning the year 2020, taking a value of $159 \mathrm{GW} \cdot \mathrm{s}$.

\section{Scenario 1}

In this scenario, the total kinetic energy is the same as Scenario 0, but there will be introduced variable speed capabilities at three of the systems powerplants. Two powerplants over $100 \mathrm{MW}$, are replaced with DFIM technology and one medium-sized hydropower generation unit will be substituted with CFSM. The total production capacity of variable-speed hydropower plants installed in the NPS is 374 MVA. The location of the different varied speed installations in the model are summarized in Table 4.

Table 4. Varied speed installations in the NPS model in the year 2030.

\begin{tabular}{ccc}
\hline Power Station & Installed Capacity (MVA) & New Technology \\
\hline Såheim & 189 & DFIM \\
Hjartdøla & 130 & DFIM \\
Fjone & 55 & CFSM \\
\hline
\end{tabular}

Scenario 2

Scenario 2 will follow the same pattern as Scenario 1 when it comes to the changes on the powerplants, but there will also be installed a BESS at busbar to one of the powerplants, to help with system support. The location and size of the BESS in the NPS model are shown in Table 5.

Table 5. Battery installations in the NPS model in the year 2030.

\begin{tabular}{ccc}
\hline Power Station & Installed Capacity of the Plant [MVA] & BESS Capacity (MVAh) \\
\hline Fjone & 38 & 55 \\
\hline
\end{tabular}

\subsubsection{Year 2040}

The NPS will experience a significant drop in the total kinetic energy in the year 2040 due to the expected decommission of the Swedish nuclear powerplants. In this ten-year interval, the peak consumption will exceed the installed capacity of regulated power in the NPS. As a consequence, the NPS will be more dependent on a more flexible power supply from the regulatable power sources, to keep a stable system frequency and it will also require the introduction of synthetic inertia to ensure a satisfactory level of inertia in the system.

CFSM will become the dominant technology of variable-speed hydropower plants when it comes to power applications less than $100 \mathrm{MW}$. It is also expected that BESS declining in price, so it could be even more attractive to be used as system support in the NPS.

Scenario 0

Year 2040 will experience a reduction of the total kinetic energy of the NPS around $39.66 \%$ regarding the year 2020, taking a value of $105 \mathrm{GW} \cdot \mathrm{s}$. In this scenario, it is only expected to be done maintenance and retrofitting to a level that all the power stations have the same capabilities as they have in today's NPS.

\section{Scenario 1}

In the year 2040, in addition to the three powerplants already installed in the year 2030 two DFIM (Såheim and Hjartdøla) and one CFSM (Fjone), it will be retrofitted four powerplants with 
varied speed hydro. From the four powerplants retrofitted, one powerplant over $100 \mathrm{MW}$ is replaced with DFIM technology, and three medium-sized hydropower are substituted with CFSM since it is expected that CFSM will be the dominating technology on the market at this time. The total number of variable-speed hydropower plants installed in the NPS is seven, and its total capacity is 794 MVA. Summarization of all the varied speed hydro installations in the NPS model is shown in Table 6.

Table 6. Varied speed installations in the NPS model in the year 2040.

\begin{tabular}{ccc}
\hline Power Station & Installed Capacity (MVA) & New Technology \\
\hline Såheim & 189 & DFIM \\
Hjartdøla & 130 & DFIM \\
Mår & 190 & DFIM \\
Fjone & 55 & CFSM \\
Mæl & 38 & CFSM \\
Skollenborg & 99 & CFSM \\
Svelgfoss & 93 & CFSM \\
\hline
\end{tabular}

\section{Scenario 2}

Scenario 2 considered the same powerplants retrofitted as in Scenario 1, with the same type of technology choice. In this scenario, in addition to the BESS installed in the year 2030 (Fjone), it will also be introduced four BESS in different sizes, providing a total of 275 MVA. The location and capacity of all the installed BESS are shown in Table 7.

Table 7. Battery installation in the NPS model in the year 2040.

\begin{tabular}{ccc}
\hline Power Station & Installed Capacity of the Plant (MVA) & BESS Capacity (MVAh) \\
\hline Fjone & 38 & 55 \\
Mæl & 38 & 38 \\
Fritzøe & 7 & 7 \\
Skollenborg & 99 & 99 \\
Svelgfoss & 93 & 93 \\
\hline
\end{tabular}

\section{Simulation and Results}

\subsection{Vestfold and Telemark System}

The authors of this research paper developed a network model of the Vestfold and Telemark area in Norway using data publicly available; as a consequence, the model may have discrepancies to the real model. The network model represents the $132 \mathrm{kV}$ network in the geographical area of Vestfold and Telemark interconnected to the Norwegian power system at $420 \mathrm{kV}$ and $300 \mathrm{kV}$. The network consists of 109 busbars from $11 \mathrm{kV}$ (generation voltage level) up to $420 \mathrm{kV}$ and the total active power demand in the regional system is $P_{d}=1643 \mathrm{MW}$ divided between 58 different lumped loads in varying sizes, from $16 \mathrm{MW}$ and up to $62 \mathrm{MW}$. The total installed capacity in the regional network is $P_{G}=1083 \mathrm{MVA}$ divided between 20 hydropower generation units (from 2.3 MVA up to 190 MVA). The Vestfold and Telemark network imports $P_{t i e}=560 \mathrm{MW}$ from the Norwegian power system to cover the total power demand. Figure 9 shows a geographical representation of the Vestfold and Telemark power system, where the green areas represent the loads and the red areas represent the hydropower generation units.

The scenarios defined in the previous section are assessed considering a frequency disturbance applied to the power system at $t=0 \mathrm{~s}$ and observing the indicators of the frequency of the centre of inertia $\left(f_{\mathrm{COI}}\right)$ : maximum frequency deviation $\left(\Delta f_{\mathrm{COI}}, \max \right)$, minimum frequency $\left(f_{\mathrm{COI}, \text { min }}\right)$, minimum time $\left(t_{C O I}\right.$, min $)$, the maximum rate of change of frequency $\left(R O C O F_{C O I}\right.$ max $)$, and steady-state frequency $\left(f_{\mathrm{COI}, s s}\right)$. The frequency disturbance is defined as the sudden disconnection of a large generation unit $\Delta P=1300 \mathrm{MW}$. 


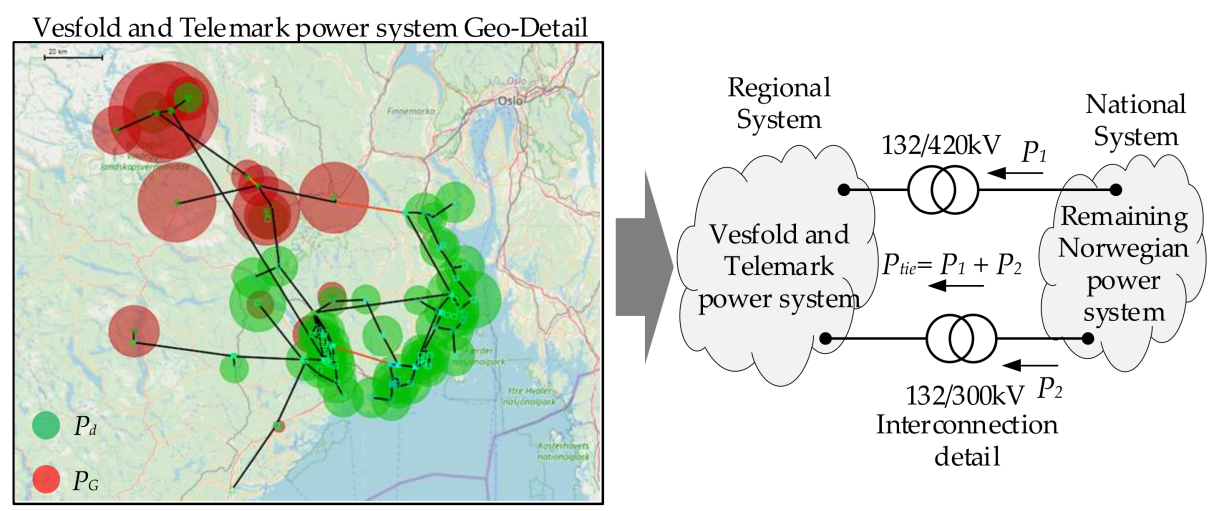

Figure 9. Geographical representation of the Vestfold and Telemark power system.

The under-frequency scheme of the Nordic power system is implemented to operate in a mandatory range, starting at a frequency level of $48.7-48.8 \mathrm{~Hz}$ until a final frequency level of $48 \mathrm{~Hz}$ [28]. Therefore, the minimum frequency $\left(f_{\mathrm{COI}}\right.$, min $)$ should not reach values below $48.7 \mathrm{~Hz}$ to avoid the trigger of the under-frequency relay, and it can be done by the implementation of the DFIM, CFSM, and BESS technologies.

The described power is modelled in DIgSILENT ${ }^{\circledR \circledR}$ PowerFactory $^{\mathrm{TM}}$ version 2020 to assess the performance of the system frequency response, a closed-loop framework using Python is used to automatize simulation during the optimization purpose. The optimization procedure was performed using the Sequential Least SQuares Programming method [29]. The simulation process consists of time-domain simulations using RMS values from DIgSILENT ${ }^{\circledR}{ }^{\circledR}$ PowerFactory ${ }^{\mathrm{TM}}$ to obtain the frequency response of Vestfold and Telemark power system. The total simulation time is $150 \mathrm{~s}$ since this timescale is adequate to replicate the phenomenon related to the electromechanical variables. Moreover, Scenario 0, Scenario 1, and Scenario 2 of each ten-year interval were used to assess the performance of the frequency response considering the effect of the DFIM, CFSM and BESS technologies.

\subsection{Base Case: Scenario 0}

Scenario 0 denotes the outlook at which the NPS does not create any changes on the hydropower plants thought the 2020-2040 period; the only maintenance is carried out on the hydropower plants. However, during the 2020-2040 period, the NPS suffers a decreasing of the total kinetic energy of $8.62 \%$ and $39.66 \%$ regarding the year 2020, respectively. The decreases in the kinetic energy produce a deterioration in the frequency response after being inserted a frequency disturbance $(\Delta P=1300 \mathrm{MW}$ at $t=0 \mathrm{~s})$ as shown in Figure 10.

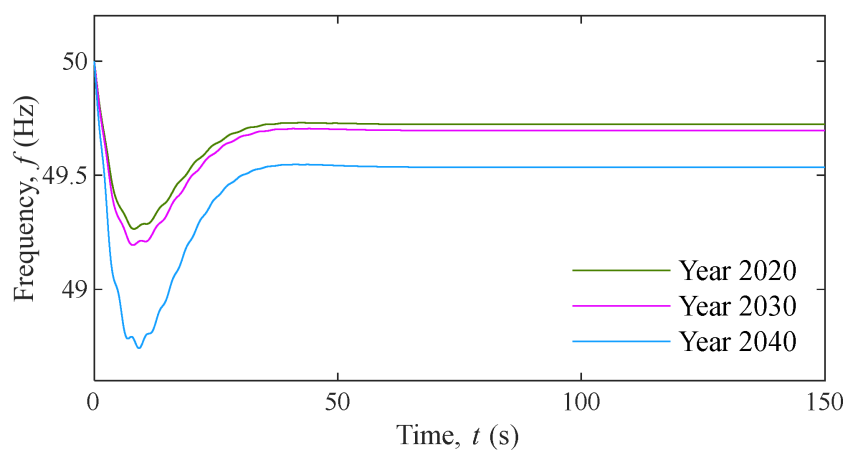

Figure 10. Comparison of the frequency response for decreasing the kinetic energy in the period 2020-2040 on Scenario 0.

Although the frequency is recovered after a few seconds and the power system remains stable on the three ten-year intervals (2020, 2030, and 2040), the frequency indicators are several affected 
by the decreasing of the kinetic energy as described in Table 8. As the kinetic energy decreases, the frequency minimum $\left(f_{\mathrm{COI}}, \mathrm{min}\right)$ reaches its deepest values and, as a consequence, the maximum frequency deviation $\left(\Delta f_{C O I}, \max \right)$ grows. Moreover, the speed at which the frequency falls in the year 2040 (i.e., the maximum ROCOF (ROCOF COI $\left._{\max }\right)$ ) increases by approximately $41.5 \%$ concerning the year 2020. The deteriorating of these indicators is directly related to the inertial response since the synchronous generators do not have enough energy stored on its rotating masses to try to arrest the frequency drop.

Table 8. Summary of frequency response indicators for Scenario 0: the year 2020, 2030, and 2040.

\begin{tabular}{|c|c|c|c|c|c|c|}
\hline Year & $\begin{array}{c}\text { Total Kinetic Energy } \\
\text { (GW·s) }\end{array}$ & $\underset{(\mathbf{H z})}{\Delta f_{\text {COI, max }}}$ & $\begin{array}{c}f_{C O I, \min } \\
(\mathbf{H z})\end{array}$ & $\begin{array}{c}t_{\min } \\
\text { (s) }\end{array}$ & $\underset{(\mathrm{Hz} / \mathrm{s})}{\operatorname{ROCOF}_{C O I, \max }}$ & $\begin{array}{l}f_{\text {COI, ss }} \\
(\mathbf{H z})\end{array}$ \\
\hline 2020 & 174 & 0.738 & 49.265 & 8.132 & -0.186 & 49.723 \\
\hline 2030 & 159 & 0.806 & 49.194 & 7.912 & -0.204 & 49.697 \\
\hline 2040 & 105 & 1.258 & 48.742 & 9.182 & -0.318 & 49.536 \\
\hline
\end{tabular}

From the results of Table 8 , it is necessary to include other technologies that can provide frequency support, especially in the year 2040, where the grates drop of inertia occurs. In the year 2040, $f_{\mathrm{COI} \text {, min }}$ reaches values that are on the under-frequency load shedding operation zone, and it can produce the activation of the under-frequency relays and start an unnecessary load shedding or even worst produce an instability condition.

\subsection{Optimized Response: Scenario 1 and Scenario 2}

This section is dedicated to assessing the solution of the objective function formulated in (13), which the primary purpose is minimizing the maximum frequency deviation of the frequency of the centre of inertia $\left(\Delta \mathrm{f}_{\mathrm{COI}, \max }\right)$ and compute the optimal settings of the droop coefficients of the DFIM $\left(K_{d, \alpha}\right), \operatorname{CFSM}\left(K_{d, \beta}\right)$ and BESS $\left(K_{d, \gamma, k}\right)$ technologies. In this stage, Scenario 1 and Scenario 2 are evaluated, Scenario 1 denotes the perspective of substituting several big and medium hydropower plants by DFIM and CFSM technologies, respectively. Meanwhile, Scenario 2 considers replacing big and medium hydropower plants with DFIM and CFSM technologies and additionally install several BESS at a key point of the NPS.

\subsubsection{Year 2030}

For this year, the objective function defined in (13) is evaluated to compute the optimal droop coefficients $\left(K_{d, \alpha}, K_{d, \beta}\right.$ and $\left.K_{d, \gamma}\right)$ of Scenario 1 and Scenario 2 . The optimization solution is presented in Table 9.

Table 9. Optimal droop coefficients $\left(K_{d, \alpha}, K_{d, \beta}\right.$ and $\left.K_{d, \gamma}\right)$ of Scenario 1 and Scenario 2 in the year 2030.

\begin{tabular}{cccc}
\hline Power Station & Technology & Scenario 1 & Scenario 2 \\
\hline Såheim & DFIM & 0.0001 & 0.0001 \\
Hjartdøla & DFIM & 0.0072 & 0.0001 \\
Fjone & CFSM & 0.052 & 0.0001 \\
Fjone & BESS & - & 0.0001 \\
\hline
\end{tabular}

The optimal coefficients obtained from the optimization are used to set the parameters of the PFAP controllers, and system frequency is evaluated by inserting a frequency disturbance of $\Delta P=1300 \mathrm{MW}$ at $t=0 \mathrm{~s}$. The frequency response of Scenario 0, Scenario 1, and Scenario 2 is shown in Figure 11. 


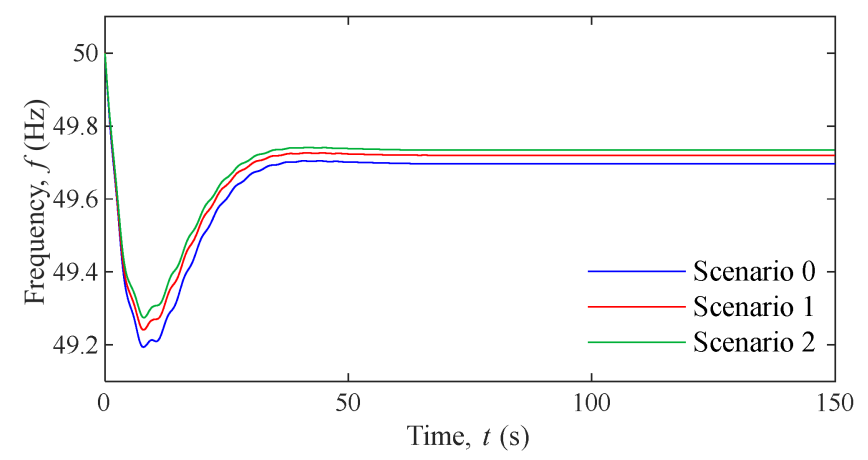

Figure 11. Frequency response after inserting a frequency disturbance of $\Delta P=1300 \mathrm{MW}$ at $t=0 \mathrm{~s}$ with a total kinetic energy of 159 GW.s.

From Figure 11, it is evident that the frequency response was improved by the inclusion of DFIM and CFSM technologies for Scenario 1 regarding Scenario 0. Moreover, in Scenario 2, the frequency response was enhanced concerning Scenario 1 due to the inclusion of BESS. The improvement of the frequency response in Scenarios 1 and Scenario 2 was mainly related to the fast action of the PFAP controllers, since those controllers deliver the proper amount of active power to stop the frequency deviation. The total active power contribution of the power plants to the disturbance is presented in Figure 12.

The frequency response indicators of the three scenarios assessed in the year 2030 are depicted in Table 10. this table, it is possible to observe that the optimized PFAP controller can improve the frequency response indicators concerning Scenario 0, even when the total kinetic energy decreased regarding the year 2020.

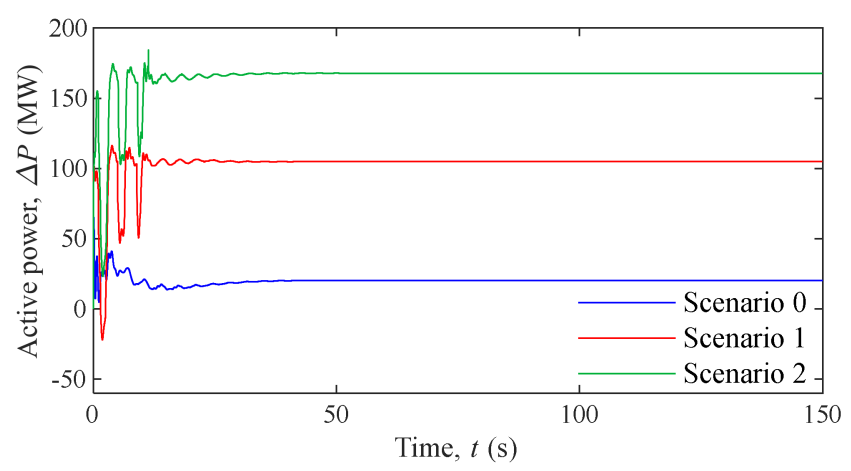

Figure 12. Total active power contribution of synchronous generators (Scenario 0), synchronous generators, DFIM and CFSM (Scenario 1) and synchronous generators, DFIM, CFSM and BESS (Scenario 2) in the year 2030.

Table 10. Frequency response indicators of Scenario 0, Scenario 1 and Scenario 2 in the year 2030.

\begin{tabular}{cccccc}
\hline Scenario & $\begin{array}{c}\Delta f_{\text {COI, max }} \\
(\mathbf{H z})\end{array}$ & $\begin{array}{c}f_{\text {COI, min }} \\
\mathbf{( H z )}\end{array}$ & $\begin{array}{c}\boldsymbol{t}_{\text {min }} \\
\mathbf{( s )}\end{array}$ & $\begin{array}{c}\text { ROCOF } \\
\mathbf{( H z / s )}\end{array}$ & $\begin{array}{c}f_{\text {COI, ss }} \\
(\mathbf{H z})\end{array}$ \\
\hline 0 & 0.806 & 49.194 & 7.912 & -0.204 & 49.697 \\
1 & 0.759 & 49.241 & 7.912 & -0.195 & 49.720 \\
2 & 0725 & 49.275 & 7.995 & -0.196 & 49.734 \\
\hline
\end{tabular}

Figure 13 presents the minimum frequency $\left(f_{\min }\right)$ and the maximum ROCOF that the synchronous generator experiences in Scenario 1 and Scenario 2. This figure shows that the inclusion of BESS makes that $f_{\min }$ of all synchronous generators connected to the NPS reduces and the maximum ROCOF has a slight decrease. 


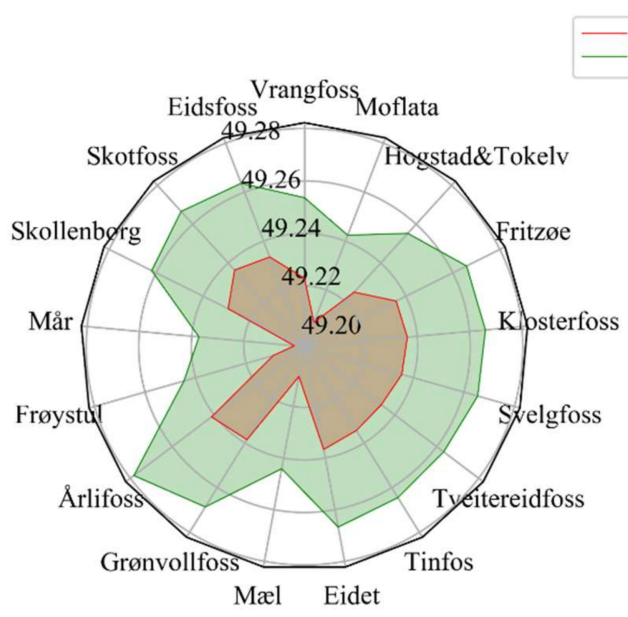

(a)

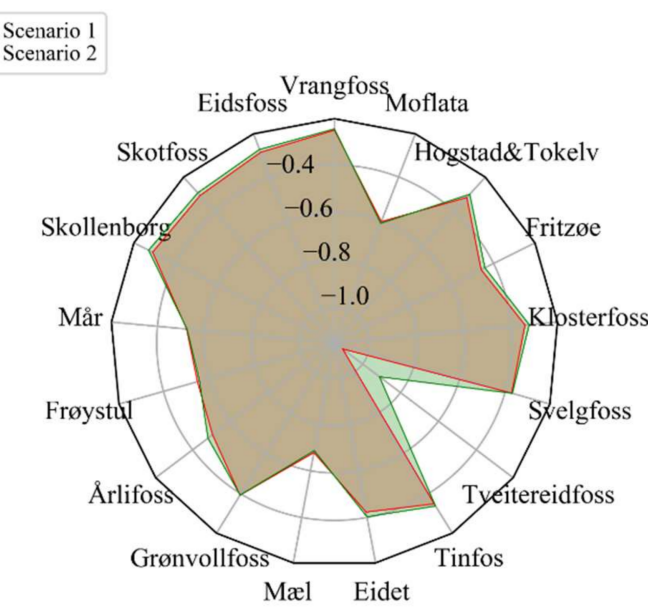

(b)

Figure 13. Frequency indicators of the synchronous generators in operation for Scenario 1 and Scenario 2 of the year 2030: (a) minimum frequency $\left(f_{\min }\right)$ and $(\mathbf{b})$ Maximum ROCOF.

\subsubsection{Year 2040}

The year 2040 is critical due to the fact that it experience a substantial decrease in total kinetic energy (around 39.66\% regarding the year 2020), and it produces that the minimum frequency reaches values inside the operation zone of the under-frequency loads shedding. For this year, the objective function defined in (13) is evaluated to compute the optimal droop coefficients $\left(K_{d, \alpha}, K_{d, \beta}\right.$ and $\left.K_{d, \gamma}\right)$ of Scenario 1 and Scenario 2 and the optimization solution is presented in Table 11.

Table 11. Optimal droop coefficients $\left(K_{d, \alpha}, K_{d, \beta}\right.$ and $\left.K_{d, \gamma}\right)$ of Scenario 1 and Scenario 2 in the year 2040.

\begin{tabular}{cccc}
\hline Power Station & Technology & Scenario 1 & Scenario 2 \\
\hline Såheim & DFIM & 0.0001 & 0.0001 \\
Hjartdøla & DFIM & 0.0975 & 0.0001 \\
Mår & DFIM & 0.0001 & 0.0001 \\
Fjone & CFSM & 0.0126 & 0.0001 \\
Mæl & CFSM & 0.0001 & 0.0001 \\
Skollenborg & CFSM & 0.0152 & 0.0001 \\
Svelgfoss & CFSM & 0.0298 & 0.0001 \\
Fjone & BESS & - & 0.0001 \\
Mæl & BESS & - & 0.0001 \\
Fritzøe & BESS & - & 0.0001 \\
Skollenborg & BESS & - & 0.0001 \\
Svelgfoss & BESS & - & 0.0001 \\
\hline
\end{tabular}

The optimal coefficients obtained from the optimization were used to set the parameters of the PFAP controllers, and the system frequency was evaluated by inserting a frequency disturbance of $\Delta P=1300 \mathrm{MW}$ at $t=0 \mathrm{~s}$. Figure 14 depicts the frequency response of the Scenario 0 , Scenario 1 and Scenario 2. In this figure, it can be observed that Scenario 1 and Scenario 2 presents an improvement in the frequency response compared with Scenario 0. Moreover, in Scenario 2, the minimum frequency significantly decreases in comparison with Scenario 1. The slight drop of frequency, around $80 \mathrm{~s}$ in Scenario 2, was produced by the discharge of the BESS, they already delivered the active power to arrest the frequency decline and to reduce the minimum frequency, and then start the charging process. This process is clearly shown in Figure 15, where the total contribution of active power is shown. 


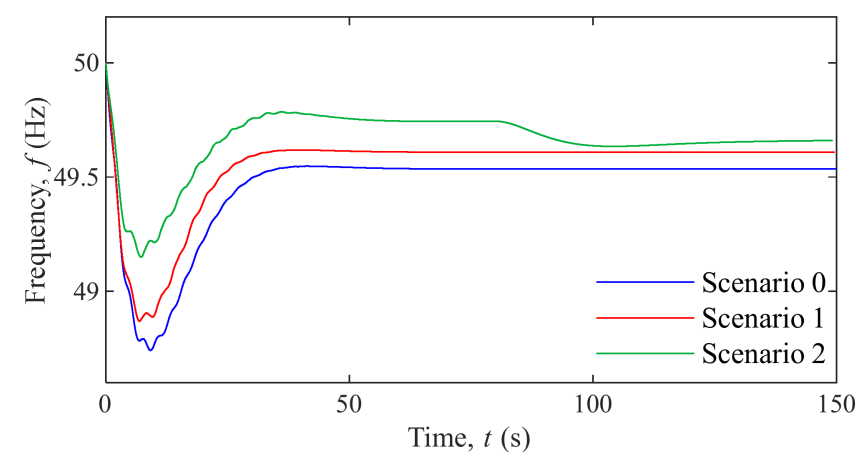

Figure 14. Frequency response after inserting a frequency disturbance of $\Delta P=1300 \mathrm{MW}$ at $t=0 \mathrm{~s}$, with a total kinetic energy of 105 GW.s.

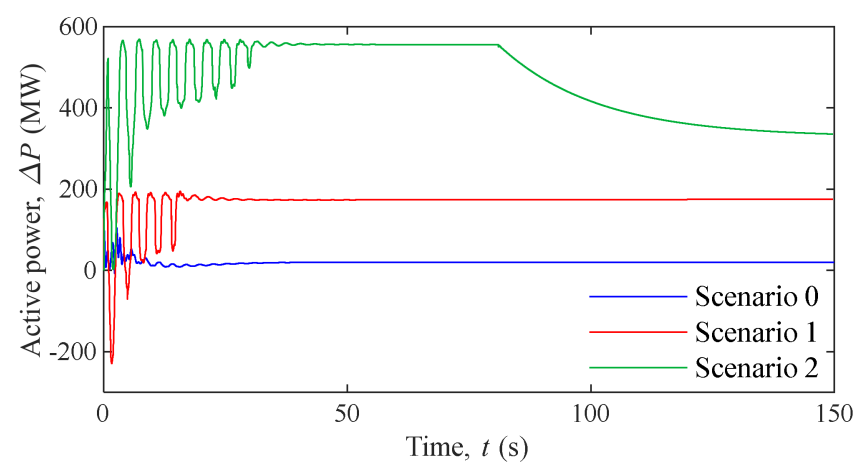

Figure 15. Total active power contribution of synchronous generators (Scenario 0), synchronous generators, DFIM and CFSM (Scenario 1) and synchronous generators, DFIM, CFSM and BESS (Scenario 2) in the year 2040.

Table 12 presents the frequency response indicators of the three scenarios assessed in the year 2040. From this table, the Scenario 1 and Scenario 2 shows that the optimal parameters of PFAP controller can significantly enhance the frequency response indicators concerning to Scenario 0 to face an important decreasing in the total kinetic energy, as considered in the year 2040. The installation of variable-speed hydropower technologies in the NPS allows reducing the minimum frequency of $0.127 \mathrm{~Hz}$ and the maximum ROCOF $0.036 \mathrm{~Hz} / \mathrm{s}$ moving the frequency out of the under-frequency load shedding operation zone. However, the minimum frequency value remains near to the under-frequency load shedding operation zone. Scenario 2, which includes the installation of BESS, present a significant diminution of the maximum frequency deviation of $0.408 \mathrm{~Hz}$, which places the minimum frequency outside the zone of the under-frequency load shedding activation. The maximum ROCOF, as well as the steady-state frequency, are improved.

Table 12. Frequency response indicators of Scenario 0, Scenario 1 and Scenario 2 in the year 2040.

\begin{tabular}{cccccc}
\hline Scenario & $\begin{array}{c}\Delta f_{\text {COI, max }} \\
\mathbf{( H z )}\end{array}$ & $\begin{array}{c}f_{\text {COI, min }} \\
\mathbf{( H z )}\end{array}$ & $\begin{array}{c}\boldsymbol{t}_{\text {min }} \\
\mathbf{( s )}\end{array}$ & $\begin{array}{c}\text { ROCOF } \\
\mathbf{( H z} / \mathbf{s})\end{array}$ & $\begin{array}{c}f_{\text {COI, } \text { max }} \\
\mathbf{( H z )}\end{array}$ \\
\hline 0 & 1.258 & 48.742 & 9.182 & -0.318 & 49.536 \\
1 & 1.131 & 48.869 & 6.905 & -0.282 & 49.609 \\
2 & 0.850 & 49.150 & 7.223 & -0.274 & 49.660 \\
\hline
\end{tabular}

Figure 16 shows that the minimum frequency and the maximum ROCOF of the synchronous generators connected to the NPS are substantially improved with the inclusion of BESS as frequency support. 


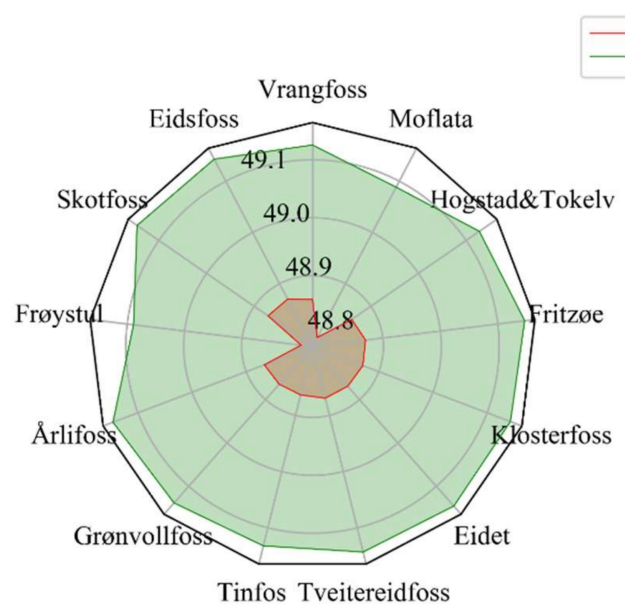

(a)

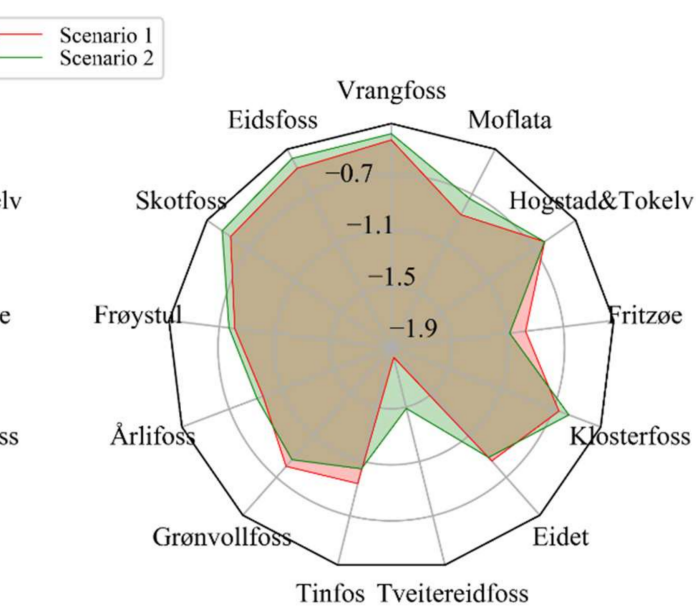

(b)

Figure 16. Frequency indicators of the synchronous generator in operation for Scenario 1 and Scenario 2 of the year 2040: (a) minimum frequency $\left(f_{\min }\right)$ and $(\mathbf{b})$ Maximum ROCOF.

Due to the converter decouples DFIM, CFSM, and BESS technologies from the source (the primary source had enough energy to cope with the frequency support) they were the same in the sense of active power delivery, and the optimal droop coefficients $\left(K_{d, \alpha}, K_{d, \beta}\right.$, and $\left.K_{d, \gamma}\right)$ of the PFAP controller are computed based on the active power available to deliver and the frequency deviation. Therefore, the optimal droop coefficients obtained from the optimization process for Scenario 2 indicates that DFIM, CFSM and BESS have the same rate to deliver the active power, i.e., the droop coefficients forces the source to deliver the active power at the maximum rate (0.001) in order to provide a quick active power response and avoid the frequency drops below $48.7 \mathrm{~Hz}$.

\section{Conclusions}

The simulation results show that retrofitting the conventional hydropower plants by incorporating variable-speed technologies in the upcoming years will allow dealing with the problem of increasing renewable sources and the decreasing of the system inertia in the NPS. In the future, the hydropower units will require to be more flexible, and this flexibility can be reached by the incorporation of variable speed technologies, which provide more efficient than conventional hydropower units when the generation units are producing outside its rated head/output values.

The approaches presented in this paper demonstrates the positive benefits of incorporating the doubly fed induction machine, converter-fed synchronous machine and battery energy storage system technologies as a reliable tool to ensure the frequency stability of the NPS in the perspective of disconnection of several thermal and nuclear power plants and therefore low levels of kinetic energy. The doubly fed induction machine and converter-fed synchronous machine technologies shown superior performance compared with the synchronous generators since those technologies can modify the active power depending on the speed variation range and therefore, resulting in a high ability to regulate the frequency especially in scenarios of low kinetic energy. Moreover, the incorporation of the battery energy storage system provides frequency support by supplying fast active power, covering the lack of active power, especially in scenarios of great inertia reduction such in the year 2040.

The optimization of the parameters of the PFAP controller allows for providing the optimal amount of active power to recover the frequency deviation. Furthermore, the optimal values of the droop coefficients allow stopping the frequency de decaying and avoid the under-frequency load shedding relays activation. In addition, the formulation to optimize the droop coefficients permit limited the minimum frequency and therefore, substantially improved the frequency response indicators when doubly fed induction machine, converter-fed synchronous machine and battery energy storage system technologies are installed in the NPS. 
Author Contributions: Conceptualization, F.G.-L., D.P. and J.P.A.; methodology, M.N.A. and D.P.; software, M.N.A. and D.P.; validation, F.G.-L., J.P.A. and M.A.A.; formal analysis, M.N.A.; investigation, M.N.A. and D.P.; resources, F.G.-L.; data curation, D.P.; writing—original draft preparation, M.N.A.; writing—review and editing, F.G.-L., J.P.A., M.A.A.; visualization, M.N.A. and D.P.; supervision, F.G.-L., J.P.A. and M.A.A. All authors have read and agreed to the published version of the manuscript.

Funding: This research received no external funding.

Acknowledgments: The authors would like to thank the support of University of South-Eastern Norway and Gamesa Electric. Martha N. Acosta would like to acknowledge the support given by CONACYT (México) and Universidad Autónoma de Nuevo León.

Conflicts of Interest: The authors declare no conflict of interest.

\section{References}

1. Statista. Available online: https://www.statista.com/statistics/864429/total-hydropower-capacity-in-sweden/ (accessed on 23 April 2020).

2. Lia, L.; Jensen, T.; Stensby, K.E.; Holm Midttømme, G.; Ruud, A.M. The current status of hydropower development and dam construction in Norway. Int. J. Hydropower Dams. 2015, 22, 37-43.

3. Electricity Production-Energifakta Norge. Available online: https://energifaktanorge.no/en/norsk-energifor syning/kraftproduksjon/ (accessed on 23 April 2020).

4. Erlend Løklingholm, E. Design and Operation Investigations for Large Converter-Fed Synchronous Machines in Hydropower Applications. Ph.D. Thesis, Norwegian University of Science and Technology (NTNU), Trondheim, Norway, 2019.

5. Skytte, K.; Bergaentzlé, C.; Junqueira Fausto, F.; Andreas Gunkel, P. Flexible Nordic Energy System: Summary Report; Nordic Energy Research: Oslo, Norway, 2019; pp. 1-120, ISBN 9788793458659.

6. Kerkman, R.J.; Lipo, T.A.; Newman, W.G.; Thirkell, J.E. An Inquiry into Adjustable Speed Operation of a Pumped Hydro Plant Part 1-Machine Design and Performance. IEEE Trans. Power Appar. Syst. 1980, PAS-99, 1828-1837. [CrossRef]

7. U.S. Army Corps of Engineers Division. Technical Analysis of Pumped Storage and Integration with Wind Power in the Pacific Northwest Final Report; MWH Americas Inc.: Portland, OR, USA, 2009; pp. 1-166.

8. Raabe, J. Hydro Power: The Design, Use, and Function of Hydromechanical, Hydraulic, and Electrical Equipment; VDI-Verlag, Ed.; VDI-Verlag GmbH: Dusseldorf, Germany, 1985; ISBN 3184006166.

9. Tehri Pumped Storage Plant-Power Technology|Energy News and Market Analysis. Available online: https://www.power-technology.com/projects/tehri-pumped-storage-plant/ (accessed on 25 April 2020).

10. AVČE Pumped Storage Power Plant on the Soča river: Rudis. Available online: https://www.rudis.si/en/refe rence/avce-pumped-storage-power-plant-on-the-soca-river/ (accessed on 25 April 2020).

11. Omarugawa Pumped Storage Power Plant Japan-GEO. Available online: http://globalenergyobservatory.or g/geoid/45067 (accessed on 25 April 2020).

12. Snapshots of Pumped-Storage Projects-Hydro Review. Available online: https://www.hydroreview.com/20 08/12/01/snapshots-of-pumped-storage-projects/\#gref (accessed on 25 April 2020).

13. Limmern Pumped Storage Power Plant. Available online: https://www.axpo.com/ch/en/about-us/energy -knowledge.detail.html/energy-knowledge/limmern-pumped-storage-power-plant.html (accessed on 25 April 2020).

14. Valavi, M.; Nysveen, A. Variable-Speed Operation of Hydropower Plants: A Look at the Past, Present, and Future. IEEE Ind. Appl. Mag. 2018, 24, 18-27. [CrossRef]

15. Kougias, I.; Aggidis, G.; Avellan, F.; Deniz, S.; Lundin, U.; Moro, A.; Muntean, S.; Novara, D.; Pérez-Díaz, J.I.; Quaranta, E.; et al. Analysis of emerging technologies in the hydropower sector. Renew. Sustain. Energy Rev. 2019, 113, 109257. [CrossRef]

16. Converting to Variable Speed at a Pumped-Storage Plant-Hydro Review. Available online: https://www.hy droreview.com/2013/09/01/converting-to-variable-speed-at-a-pumped-storage-plant/\#gref (accessed on 25 April 2020).

17. Estorage. Available online: https://www.estorage-project.eu/wp-content/uploads/2013/06/eStorage-D1.3-Rep ort-on-Le-Cheylas-upgrade-studies.pdf (accessed on 18 April 2020).

18. Hadjipaschalis, I.; Poullikkas, A.; Efthimiou, V. Overview of current and future energy storage technologies for electric power applications. Renew. Sustain. Energy Rev. 2009, 13, 1513-1522. [CrossRef] 
19. Weitzel, T.; Glock, C.H. Energy management for stationary electric energy storage systems: A systematic literature review. Eur. J. Oper. Res. 2018, 264, 582-606. [CrossRef]

20. U.S. Department of Energy DOE OE Global Storage Database. Available online: https://www.sandia.gov/ess -ssl/global-energy-storage-database-home/ (accessed on 16 March 2020).

21. Farhadi, M.; Mohammed, O. Energy Storage Technologies for High-Power Applications. IEEE Trans. Ind. Appl. 2016, 52, 1953-1961. [CrossRef]

22. Gonzalez-Longatt, F.M. Effects of Fast Acting Power Controller of BESS in the System Frequency Response of a Multi-Machine System: Probabilistic Approach. In Proceedings of the 2018 IEEE Innovative Smart Grid Technologies-Asia (ISGT Asia), Perth, Australia, 22-25 May 2018; pp. 804-809.

23. Krechel, T.; Sanchez, F.; Gonzalez-Longatt, F.; Chamorro, H.; Rueda, J.L. Transmission system-friendly microgrids: An option to provide ancillary services. In Distributed Energy Resources in Microgrids; Elsevier: Amsterdam, The Netherlands, 2019; pp. 291-321, ISBN 9780128177747.

24. Anderson, P.M.; Fouad, A.A. Power System Control and Stability; IEEE Press: New York, NY, USA, 2003; ISBN 8126518189.

25. Gonzalez-Longatt, F.; Rueda, J.L.; Vázquez Martínez, E. Effect of Fast Acting Power Controller of Battery Energy Storage Systems in the Under-Frequency Load Shedding Scheme; Loughborough University: Loughborough, UK, 2018; ISBN 9781538642917.

26. Gonzalez-Longatt, F.; Chikuni, E.; Rashayi, E. Effects of the Synthetic Inertia from wind power on the total system inertia after a frequency disturbance. In Proceedings of the IEEE International Conference on Industrial Technology, Antalya, Turkey, 9-12 October 2013; pp. 826-832.

27. Gonzalez-Longatt, F.; Sanchez, F.; Leelaruji, R. Unveiling the Character of the Frequency in Power Systems. In Proceedings of the 2019 IEEE PES GTD Grand International Conference and Exposition Asia (GTD Asia), Bangkok, Thailand, 19-23 March 2019; pp. 57-62.

28. Hutchison, G.; Breidablik, Ø.; Kuisti, H.; Luukkonen, I.; Nielsen, M.; Nielsen, F.B.; Setréus, J.; Sørensen, L.G.; Turunen, J. Frequency Based Emergency Disconnection Policy Review for the Nordic Region; ENTSO-E: Brussels, Belgium, 2017; pp. 1-75.

29. Kraft, D.; DFVLR-FB. A Software Package for Sequential Quadratic Programming; DLR German Aerospace Center-Intitute for Flight Mechanics: Koln, Germany, 1988. 